\title{
An Enantioselective Approach to the Preparation of Chiral Sulfones by Ir-Catalyzed Asymmetric Hydrogenation
}

\author{
Byron K. Peters, ${ }^{\dagger, \S}$ Taigang Zhou, ${ }^{\dagger, \S}$ Janjira Rujirawanich, ${ }^{\ddagger}$ Alban Cadu, ${ }^{\ddagger}$ Thishana Singh, ${ }^{\dagger, \ddagger}$
}

Wangchuk Rabten, ${ }^{\dagger}$ Sutthichat Kerdphon, ${ }^{\dagger}$ and Pher G. Andersson* ${ }^{\dagger}$

${ }^{\dagger}$ Department of Organic Chemistry, Stockholm University, S-10691 Stockholm, Sweden

${ }^{\ddagger}$ Department of Chemistry-BMC, Uppsala University, Box 576, S-75123 Uppsala, Sweden

\section{Supporting Information}

ABSTRACT: Several chiral sulfonyl compounds were prepared using the iridium catalyzed asymmetric hydrogenation reaction. Vinylic, allylic and homoallylic sulfone substitutions were investigated, and high enantioselectivity is maintained regardless of the location of the olefin with respect to the sulfone. Impressive stereoselectivity was obtained for dialkyl substitutions, which typically are challenging substrates in the hydrogenation. As expected, the more bulky $Z$-substrates were hydrogenated slower than the corresponding $E$ isomers, and in slightly lower enantioselectivity.

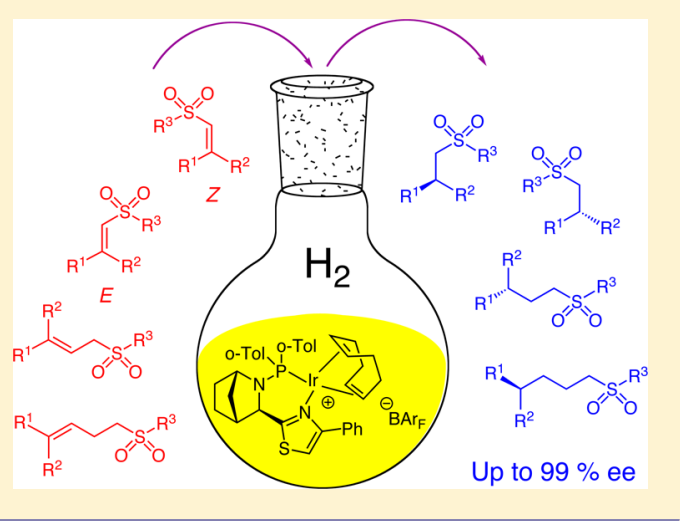

\section{INTRODUCTION}

The sulfonyl group has tremendous applications in $\mathrm{C}-\mathrm{C}$ and $\mathrm{C}=\mathrm{C}$ bond formation. ${ }^{1-3}$ In many cases, sulfones are generated as intermediates toward $\mathrm{C}=\mathrm{C}$ bond forming reactions: namely, the Julia reaction and the Ramberg-Bäcklund reaction, often used in the total synthesis of natural products. These reactions have made this functional group a valuable asset in multistep synthesis. In addition to being a temporary auxiliary group, chiral sulfones also appear as units in biologically active molecules: such as Remikiren, a renin inhibitor drug. ${ }^{4}$ Therefore, asymmetric methods for their preparation are highly desirable.

However, there are relatively few methods developed that enable the preparation of chiral sulfones. Ag-mediated ${ }^{5}$ as well as $\mathrm{Cu}^{-}{ }^{6}$ and Pd-catalyzed ${ }^{7}$ cycloadditions have furnished such chiral cyclic sulfones in good enantioselectivity. Chiral Lewis acid mediated and organo-catalyzed Diels-Alder reactions have also produced the desired targets in high enantioselectivity. Rhcatalyzed $\mathrm{C}-\mathrm{H}$ insertions have been studied, with moderate to high selectivities achieved..$^{8-13}$

Efficient methods for the preparation of acyclic chiral sulfones are even more scarce. Carretero et al. were among the first to develop asymmetric conjugate addition to unsaturated sulfones using $\mathrm{Rh}$ catalysis. Aryl boronic acids were added to 1,2 -disubstituted- $\alpha, \beta$-unsaturated sulfones using a Rh- $(S, S)$-Chiraphos catalyst. With this methodology, acyclic chiral sulfones were synthesized with reasonable stereoselectivity. ${ }^{14,15}$ Later, Carretero and co-workers also utilized this protocol to prepare acyclic analogues bearing quaternary chiral centers. ${ }^{16}$ However, one limitation of that method was the need for a 2-pyridyl group on the sulfone substrate in order for the catalyst to be active.

Organocatalytic reactions, which are capable of producing acyclic chiral sulfones in high enantioselectivity, have also been developed. Excellent work by Alexakis ${ }^{17,18}$ and Deng ${ }^{19,20}$ have produced several examples of synthesis of acyclic chiral sulfones, by Michael addition of nucleophiles to vinyl sulfone electrophiles. Asymmetric catalytic radical additions have also been reported. ${ }^{21,22}$

Undoubtedly, the development of a universal and facile method for preparation of both cyclic and acyclic chiral sulfones is desirable. The homogeneous asymmetric reduction, in particular, using $\mathrm{Ir}, \mathrm{Rh}$ and $\mathrm{Ru}$, is a very successful and well studied area of chemistry. ${ }^{23-29}$ Iridium catalyzed asymmetric hydrogenation of olefins has been an ever expanding field for several years; both the substrate scope $\mathrm{e}^{30-42}$ and number of chiral catalysts ${ }^{43,44}$ have been greatly expanded and the mechanistic aspects studied, ${ }^{45-49}$ by many groups. In particular, the recent publication by Pfaltz et al. has confirmed the $\mathrm{Ir}(\mathrm{III}) /$ $\operatorname{Ir}(\mathrm{V})$ nature of the catalysts cycle, thereby validating previous computational studies. $^{48}$

Surprisingly, only a few examples of the preparation of these versatile sulfones via reduction were reported in the literature. The hydrogenation of acyclic $\beta$-ketosulfones have been reported by several groups, where both $\mathrm{Ru}^{50-52}$ and $\mathrm{Rh}^{53}$ catalysts have been utilized to enantioselectively reduce the keto-group. However, there are only a few examples in the

Received: August 4, 2014

Published: October 9, 2014 
literature, where it is the $\mathrm{C}=\mathrm{C}$ moiety which is reduced. Pfaltz and Misun, using a semicorrin Co-catalyst, showed in two examples that they were able to reduce an $\alpha, \beta$-unsaturated sulfone, using $\mathrm{NaBH}_{4}$ as the hydride source. ${ }^{54}$ Carretero et al. have developed a good protocol for the conjugate reduction of $\alpha, \beta$-unsaturated sulfones using a $\mathrm{Cu}$ - $(R)$-BINAP catalyst. The reaction is carried out in the presence of base and $\mathrm{Ph}_{3} \mathrm{SiH}$ is used as the hydride source. ${ }^{55}$ The Ir-catalyzed hydrogenation has proven a useful method for hydrogenation of unfunctionalized as well as functionalized olefins, ${ }^{5,57}$ and we have recently communicated the successful reduction of a number of cyclic, vinylic and acyclic sulfones, via hydrogenation where ee's of up to $99 \%$ were achieved using Ir-catalysts developed in our group. $^{58}$

Here we report an extensive study of the substrate scope of unsaturated sulfones using N,P-ligated Ir-catalysts. A wide variety of substrates bearing an olefin one, two and three bonds away from the sulfonyl group were studied. To our knowledge, this is, thus far, the only methodology able to handle such a broad range of sulfone substrates and still retain high enantioselectivity.

\section{RESULTS AND DISCUSSION}

2.1. Asymmetric Hydrogenation of $\beta, \beta$-Disubstituted Vinyl Sulfones. In our initial study, a number of chiral Crabtree-type, $[(\mathrm{N}, \mathrm{P}) \operatorname{Ir}(\mathrm{COD})]^{+}\left[\mathrm{BAr}_{\mathrm{F}}\right]^{-}$catalysts, bearing either an oxazoline (ligands $\mathbf{1 a}$ and $\mathbf{1 b}$ ), imidazole (ligand 2 ) or thiazole (ligands 3-5) N,P-ligands (Figure 1) were screened

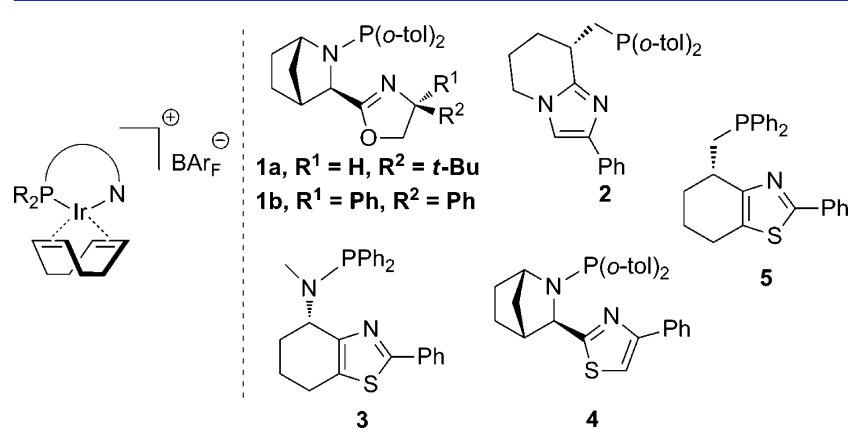

Figure 1. Catalysts and corresponding ligands used in this study.

in the asymmetric hydrogenation of model sulfone $6 c^{58,59} \mathrm{We}$ found that the iridium catalyst with thiazole-phosphine ligand 4 offered the best performance, hydrogenating $6 \mathrm{c}$ to full conversion and in $96 \%$ ee (Figure 2). We have also shown

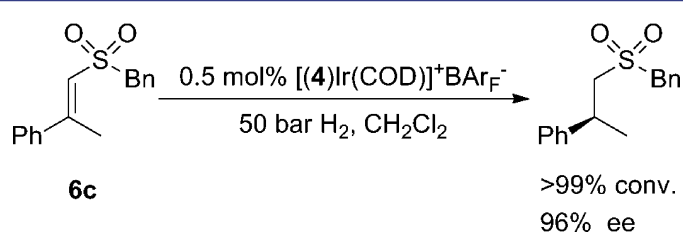

Figure 2. Asymmetric hydrogenation of model sulfone $\mathbf{6 c}$.

previously, that the catalyst bearing ligand $\mathbf{4}$ is highly active and enantioselective in the hydrogenation of a number of terminal olefins and unsaturated heterocycles. ${ }^{38,60}$

Encouraged by this result, we were interested in further study of the scope of the reaction by varying the substituents on the sulfone. It has been found that the $\mathrm{Cu}$ and $\mathrm{Rh}$ reactions are sensitive to this substitution. ${ }^{15,55}$ A variety of $E$-sulfones $(6 \mathbf{a}-\mathbf{e})$ were prepared and evaluated with the $[(4) \operatorname{Ir}(\mathrm{COD})]^{+}\left[\mathrm{BAr}_{\mathrm{F}}\right]^{-}$ catalyst (Table 1). It was found that the enantioselectivity

Table 1. Asymmetric Hydrogenation of E- and Z-Vinyl Sulfones with Different Substitution at Sulfone ${ }^{a}$

\begin{tabular}{|c|c|c|c|c|}
\hline entry & sulfone & $\mathrm{R}$ & $\begin{array}{l}\text { conv. }{ }^{\mathrm{b}} \\
\text { (\%) }\end{array}$ & $\mathrm{ee}^{\mathrm{c}}(\%)$ \\
\hline 1 & $6 a$ & $n-\mathrm{Bu}$ & $>99$ & $91(-)$ \\
\hline 2 & $6 \mathrm{~b}$ & Сy & $>99$ & $94(-)$ \\
\hline 3 & $6 c^{d}$ & $\mathrm{Bn}$ & $>99$ & $96(+)(S)$ \\
\hline 4 & $6 \mathrm{~d}$ & $\mathrm{Ph}$ & $>99$ & $94(-)$ \\
\hline 5 & $6 e$ & 2,6- $\mathrm{MeC}_{6} \mathrm{H}_{4}$ & 30 & $89(-)$ \\
\hline 6 & $7 a$ & $\mathrm{n}-\mathrm{Bu}$ & 57 & $88(+)$ \\
\hline 7 & $7 b$ & Сy & 53 & $94(+)$ \\
\hline 8 & $7 \mathrm{c}$ & $\mathrm{Bn}$ & 61 & $96(-)$ \\
\hline 9 & $7 \mathrm{~d}$ & $\mathrm{Ph}$ & 43 & $89(-)$ \\
\hline 10 & $7 \mathrm{e}$ & $2,6-\mathrm{MeC}_{6} \mathrm{H}_{4}$ & - & - \\
\hline
\end{tabular}

${ }^{a}$ Reaction conditions: $0.25 \mathrm{mmol}$ of substrate, $0.5 \mathrm{~mol} \%$ catalyst, 2 $\mathrm{mL}$ of $\mathrm{CH}_{2} \mathrm{Cl}_{2}, 50$ bar of $\mathrm{H}_{2}, 17 \mathrm{~h}$, rt. ${ }^{b}$ Conversion, determined by ${ }^{1} \mathrm{H}$ NMR spectroscopy. No side products were detected. ${ }^{c}$ Determined by chiral HPLC or GC analyses. ${ }^{d}$ See ref 58 .

remained high for the alkyl and aryl substituents in our study (89-96\% ee, entries 1-5). Both the relatively unencumbering $n$-Bu and the sterically demanding 2,6-dimethylbenzene groups afforded a drop in selectivity relative to the benzyl group (entries $1(n-\mathrm{Bu})$ and 5 (2,6-dimethyl)). Carbocyclic derivatives, benzene and cyclohexyl had similar performances and only a $2 \%$ drop in ee was observed (entries 2 and 4 ). In addition to $E$-sulfones, $Z$-sulfones were also prepared with the same sulfone substitution $(7 \mathbf{a}-\mathbf{e})$. We used the optimal iridium catalyst $\left([(4) \operatorname{Ir}(\mathrm{COD})]^{+}\left[\mathrm{BAr}_{\mathrm{F}}\right]^{-}\right)$to study the asymmetric hydrogenation of substrates with different substitution at the sulfones (Table 1). In the case of a benzyl substituent, the enantioselectivity remains equally high as in it did for the $E$ isomer (compare entries 3 and 8 , Table 1). However, in contrast with the results observed for the E-isomers, a phenyl group leads to a greater drop in enantioselectivity than in the case of the E-isomer (compare entries 4 and 9, Table 1). However, for the cyclohexyl group, the ee remains constant (compare entries 2 and 7, Table 1). A similar decrease in ee is observed for the $n$-Bu group (entry 6). The Z-2,6-dimethyl derivative, however, was found to be unreactive under the chosen conditions, most likely due to excessive steric bulk in two adjacent quadrants (see Origins of Selectivity).

Since the benzyl substituent at the sulfone proved to be the best substrate, it was kept constant for the evaluation of a series of $E$-sulfones with different substitution patterns at the $\beta$ position, using $[(4) \operatorname{Ir}(\mathrm{COD})]^{+}\left[\mathrm{BAr}_{\mathrm{F}}\right]^{-}$(Table 2). The bulk of the $\mathrm{R}^{1}$ group displayed a minor effect on selectivity. Increasing the bulk of the $\mathrm{R}^{1}$ group from $n$-Bu to $i$-Pr or Cy led to slightly lower enantioselectivities (entries 1-3). However, the asymmetric reduction of sulfone $8 \mathrm{e}$ (entry 5) underwent low selectivity $(30 \%$ ee $)$ and reactivity $(27 \%$ conv.). The substitution on the aromatic ring of the substrate (entry 7) with an electron-donating group or electron-withdrawing 
Table 2. Asymmetric Hydrogenation of $E-\beta, \beta$-Disubstituted Vinyl Sulfones ${ }^{a}$

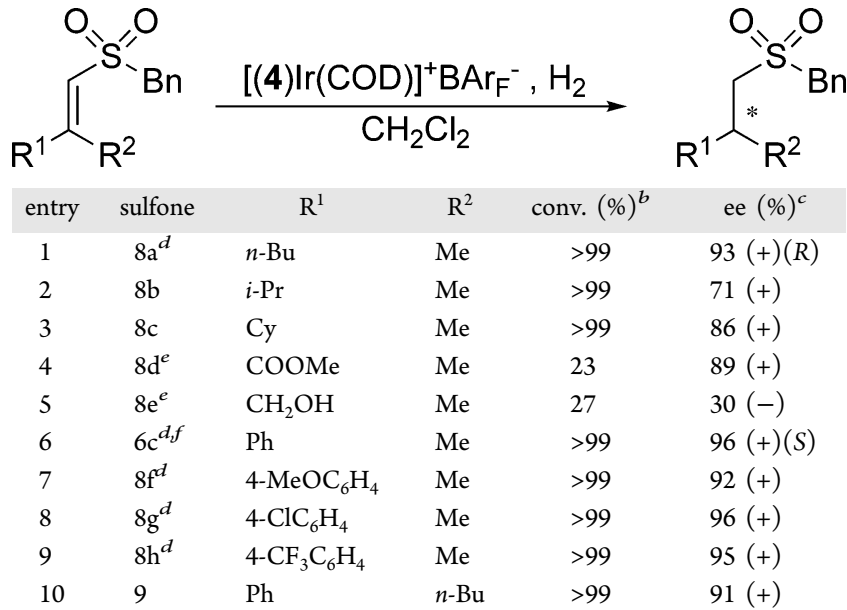

${ }^{a}$ Reaction conditions: $0.25 \mathrm{mmol}$ of substrate, $0.5 \mathrm{~mol} \%$ catalyst, 2 $\mathrm{mL}$ of $\mathrm{CH}_{2} \mathrm{Cl}_{2}, 50$ bar of $\mathrm{H}_{2}, 17 \mathrm{~h}$, rt. ${ }^{b}$ Conversion, determined by ${ }^{1} \mathrm{H}$ NMR spectroscopy. No side products were detected. ${ }^{c}$ Determined by chiral HPLC or GC analyses. ${ }^{d}$ See ref $58 .{ }^{e} \mathrm{Ph}$ on the sulfone not Bn.

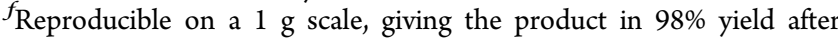
purification (see Supporting Information)

groups (entries 8-9) had little influence on the selectivity or the reactivity: all gave full conversion and excellent enantioselectivities (92-96\% ee). An increase in the size of the $\mathrm{R}^{2}$ group, from $\mathrm{Me}$ to $n-\mathrm{Bu}$, also had very little influence on the enantioselectivity of the reaction (entries 6 and 10).

Next, we studied $Z$-sulfones with a variety of substitution patterns at the $\beta$-position using $[(4) \operatorname{Ir}(\mathrm{COD})]^{+}\left[\mathrm{BAr}_{\mathrm{F}}\right]^{-}$(Table 3 ). Compared with the results in Table 2 (entries 1, 3, 6, and

Table 3. Asymmetric Hydrogenation of $Z-\beta, \beta$-Disubstituted Vinyl Sulfones ${ }^{a}$

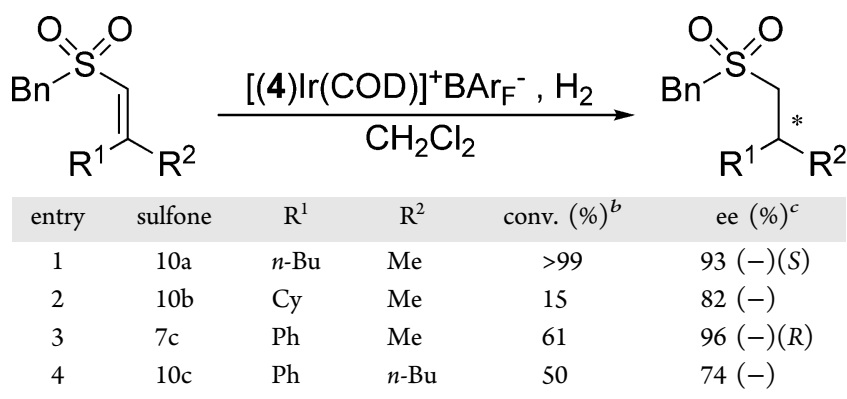

${ }^{a}$ Reaction conditions: $0.25 \mathrm{mmol}$ of substrate, $0.5 \mathrm{~mol} \%$ catalyst, 2 $\mathrm{mL}$ of $\mathrm{CH}_{2} \mathrm{Cl}_{2}, 50$ bar of $\mathrm{H}_{2}, 17 \mathrm{~h}$, rt. ${ }^{b}$ Conversion, determined by ${ }^{1} \mathrm{H}$ NMR spectroscopy. No side products were detected. ${ }^{c}$ Determined by chiral HPLC or GC analyses.

$10)$, the reactivity of $Z$-sulfones (Table 3, entry 1-4) was lower than that of $E$-sulfones. Nonetheless, $Z$-sulfones were hydrogenated in similar enantioselectivities (74-96\% ee). This meant that we could use one catalyst to hydrogenate the $E$ and/or $Z$-sulfones to produce either desired enantiomer, be it the $(S)$ - or $(R)$-enantiomer, with similar enantioselectivity.

2.2. Asymmetric Hydrogenation of $\gamma, \gamma$-Disubstituted Allylic Sulfones. Encouraged by the results achieved for $\beta, \beta$ disubstituted vinyl sulfones, we continued to study $\gamma, \gamma$ disubstituted allylic sulfones.
First, a large selection of substrates bearing different sulfone groups, ranging from the simple noncoordinating alkyl sulfones to coordinating heteroaromatic sulfones and small to bulky substituents on the sulfones were evaluated (Table 4). These

Table 4. Asymmetric Hydrogenation of E-Allylic Sulfones with Different Substitution at Sulfone ${ }^{a}$

\begin{tabular}{|c|c|c|c|c|}
\hline entry & sulfone & $\mathrm{R}$ & $\begin{array}{l}\text { conv. }^{\mathrm{b}} \\
(\%)\end{array}$ & $\mathrm{ee}^{\mathrm{c}}(\%)$ \\
\hline 1 & $11 \mathrm{a}$ & & $-{ }^{d}$ & - \\
\hline 2 & $11 \mathrm{~b}$ & & $-{ }^{d}$ & - \\
\hline 3 & $11 \mathrm{c}$ & & $>99$ & $96(-)$ \\
\hline 4 & $11 \mathrm{~d}$ & & $>99$ & $99(-)$ \\
\hline 5 & $11 \mathrm{e}$ & $-\mathrm{C}---$ & $>99$ & $97(-)$ \\
\hline 6 & $11 \mathrm{f}$ & & $>99$ & $97(-)$ \\
\hline 7 & $11 \mathrm{~g}$ & $n$-Bu----- & $>99$ & $98(-)$ \\
\hline 8 & $11 \mathrm{~h}$ & $t-\mathrm{Bu}-\cdots$ & $>99$ & $98(-)$ \\
\hline 9 & $11 \mathrm{i}$ & i-Pr----- & $>99$ & $97(-)$ \\
\hline 10 & $11 j$ & $\mathrm{MeOOCCH}_{2}^{---}$ & $>99$ & $97(-)$ \\
\hline
\end{tabular}

${ }^{a}$ Reaction conditions: $0.25 \mathrm{mmol}$ of substrate, $0.5 \mathrm{~mol} \%$ catalyst, 2 $\mathrm{mL}$ of $\mathrm{CH}_{2} \mathrm{Cl}_{2}, 50$ bar of $\mathrm{H}_{2}, 17 \mathrm{~h}$, rt. ${ }^{b}$ Conversion, determined by ${ }^{1} \mathrm{H}$ NMR spectroscopy. No side products were detected. ${ }^{c}$ Determined by chiral HPLC or GC analyses. ${ }^{d}$ No reaction.

sulfones can be used in further reactions to form the olefinic $\mathrm{C}=\mathrm{C}$ bond. For example, sulfones with an aliphatic substitution pattern can be used in the Ramberg-Bäcklund reaction to form the $\mathrm{C}=\mathrm{C}$ bond and sulfones with aromatic substituents can be used in the Julia olefination to form a different $\mathrm{C}=\mathrm{C}$ bond.

The asymmetric hydrogenation of these sulfones were carried out under conditions using $[(4) \operatorname{Ir}(\mathrm{COD})]^{+}\left[\mathrm{BAr}_{\mathrm{F}}\right]^{-}$. Full conversion and excellent enantioselectivities (96-99\% ee, entry 3-10) were achieved for all noncoordinating sulfones. Unfortunately, the sulfones bearing benzothiazo-2-yl (entry 1) and 2-pyridyl (entry 3) proved to be unreactive under these conditions. This was possibly due to heteroaromatic sulfones coordinating to the iridium catalyst.

Dialkyl allyl sulfones gave better enantioselectivities (Table 5) using ligand 1a (entries 1 and 2). With substituted aryl groups good to excellent enantioselectivities are achieved. However, bulky $2-\mathrm{MeC}_{6} \mathrm{H}_{4}$ and electron withdrawing groups 
Table 5. Asymmetric Hydrogenation of E- $\gamma, \gamma$-Disubstituted Allylic Sulfones ${ }^{a}$

\begin{tabular}{|c|c|c|c|c|c|}
\hline entry & sulfone & $\mathrm{R}$ & ligand & conv. $(\%)^{b}$ & ee $(\%)^{c}$ \\
\hline 1 & $12 a$ & $\left(\mathrm{CH}_{2}\right)_{4} \mathrm{CH}_{3}$ & 1a & $72^{d}$ & $94(+)$ \\
\hline 2 & $12 \mathrm{~b}$ & $\mathrm{Cy}$ & 1a & $62^{d}$ & $93(-)$ \\
\hline 3 & $12 \mathrm{c}$ & $\mathrm{Ph}$ & 4 & $>99^{e}$ & $99(-)$ \\
\hline 4 & $12 \mathrm{~d}$ & $2-\mathrm{MeC}_{6} \mathrm{H}_{4}$ & 4 & $14^{f}$ & $84(-)$ \\
\hline 5 & $12 \mathrm{e}$ & 4- $\mathrm{MeC}_{6} \mathrm{H}_{4}$ & 4 & $>99^{e}$ & $96(-)$ \\
\hline 6 & $12 f$ & 4- $\mathrm{ClC}_{6} \mathrm{H}_{4}$ & 4 & $>99^{f}$ & $96(-)$ \\
\hline
\end{tabular}

${ }^{a}$ Reaction conditions: $0.25 \mathrm{mmol}$ of substrate, $2 \mathrm{~mL}$ of $\mathrm{CH}_{2} \mathrm{Cl}_{2}, 50 \mathrm{bar}$ of $\mathrm{H}_{2}, 17 \mathrm{~h}$, rt. ${ }^{b}$ Conversion, determined by ${ }^{1} \mathrm{H}$ NMR spectroscopy. No side products were detected. ${ }^{c}$ Determined by chiral HPLC or GC analyses. ${ }^{d} 1 \mathrm{~mol} \%$ catalyst. ${ }^{e} 0.5 \mathrm{~mol} \%$ catalyst. $f_{2} \mathrm{~mol} \%$ catalyst.

(4- $\mathrm{ClC}_{6} \mathrm{H}_{4}$ ) required more catalyst (entries 4 and 6, respectively).

2.3. Asymmetric Hydrogenation of Diallyl Sulfone. To test the scope and limitations further, 13a was subjected to hydrogenation (Figure 3). With the use of the standard procedure, as developed on the previous substrates, the double allylic sulfone was reduced fully and selectively to the chiral diastereomer (13b) in $96 \%$ ee. This procedure would be of great value to those who are interested in the synthesis of symmetrical compounds bearing two chiral centers.

2.4. Asymmetric Hydrogenation of E-Homoallylic Unsaturated Sulfones. To further study the substrate scope, E-homoallylic unsaturated substrates with two different substitutions at the sulfone were prepared (Table 6). Benzyl and 2,6-dimethyl phenyl were chosen as R-group at the sulfone for two reasons. First, sulfones with these two groups gave excellent enantioselectivities for vinylic and allylic substrates, therefore limiting the variability to that stemming from the olefin-sulfone distance. Second, these two substituents allow for further applications: forming $\mathrm{C}=\mathrm{C}$ bond via RambergBäcklund reaction (entry 1, benzyl) and Julia olefination (entry 2, 2,6-dimethyl phenyl). As expected, these two homoallylic sulfones were reduced with full conversion and excellent enantioselectivities (94-99\% ee).

2.5. Asymmetric Hydrogenation of an $\alpha, \beta$-Substituted Unsaturated Sulfones. Moving the prostereogenicity $\alpha$ to the sulfone had no negative influence on the high enantioselectivity. Compound 15a was hydrogenated (Figure 4), producing $\mathbf{1 5 b}$ in 97 ee, exemplifying the diversity of this asymmetric hydrogenation protocol.

2.6. Ramberg-Bäcklund Reaction. As can be seen from Table 7, the Ramberg-Bäcklund reaction was performed on three substrates having the chiral center at different distances from the sulfone. The ee of the compounds remained unaffected by the reaction. While the $\beta$-substituted compound reacted to produce a good yield (entry 1 ), a somewhat lower yield was observed for entries 2 and 3 .
Table 6. Asymmetric Hydrogenation of E-Homoallylic Unsaturated Sulfones ${ }^{a}$

\begin{tabular}{|c|c|c|c|c|}
\hline entry & sulfone & $\mathrm{R}$ & conv. $(\%)^{b}$ & ee $(\%)^{c}$ \\
\hline 1 & $14 a$ & $\mathrm{Bn}$ & $>99$ & $99(-)$ \\
\hline 2 & $14 \mathrm{~b}$ & 2,6- $\mathrm{MeC}_{6} \mathrm{H}_{3}$ & $>99$ & $94(-)$ \\
\hline
\end{tabular}

${ }^{a}$ Reaction conditions: $0.25 \mathrm{mmol}$ of substrate, $0.5 \mathrm{~mol} \%$ catalyst, 2 $\mathrm{mL}$ of $\mathrm{CH}_{2} \mathrm{Cl}_{2}, 50$ bar of $\mathrm{H}_{2}, 17 \mathrm{~h}$, rt. ${ }^{b}$ Conversion, determined by ${ }^{1} \mathrm{H}$ NMR spectroscopy. No side products were detected. ${ }^{c}$ Determined by chiral HPLC or GC analyses.

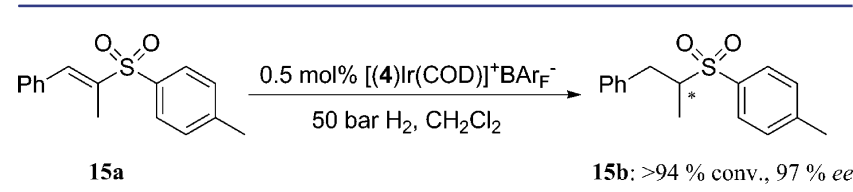

Figure 4. Asymmetric hydrogenation of $\alpha, \beta$-substituted unsaturated sulfone.

Table 7. Transformation of Chiral Sulfones by RambergBäcklund Reaction

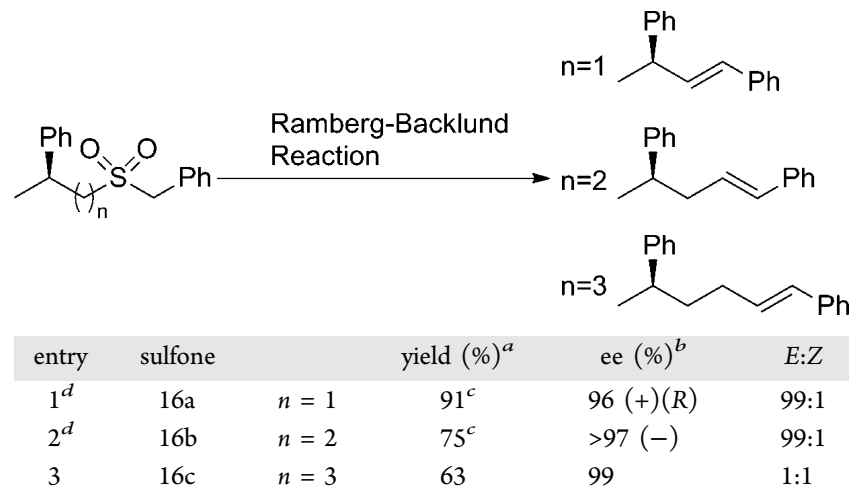

${ }^{a}$ Isolated yields. ${ }^{b}$ Determined by chiral HPLC or GC analyses. ${ }^{c}$ Only the $E$-isomer was observed. ${ }^{d}$ See ref 58.

2.7. Origins of Selectivity. The selectivity model originates from the proposed mechanism (supported by experimental data and calculations) (Figure 5A), and focuses on the steric requirements of structure (i), which is involved in the rate- and enantio-determining migratory insertion step (ii). If we consider the iridium complex used in this study (4) (Figure 5B), it is clear that most of the steric environment around the Ir arises from the aryl groups of the phosphine and the phenyl group of the thiazole.

This becomes evident in structures C and D in Figure 5, which show the steric requirements of the plane that the olefin coordinates, trans to phosphorus. This plane can be divided into four quadrants (Figure 5D,E), and it is clear that quadrant (i) in Figure 5E is very sterically hindered by the phenyl group of the thiazole, so much so that the olefin prefers to place its smallest substituent, the hydrogen (Figure 5E) in this quadrant.

$$
\overbrace{13 \mathrm{a}}^{\mathrm{Ph}} \frac{0.5 \mathrm{~mol} \%[(4) \operatorname{lr}(\mathrm{COD})]^{+} \mathrm{BAr}_{\mathrm{F}}^{-}}{50 \mathrm{bar} \mathrm{H}_{2}, \mathrm{CH}_{2} \mathrm{Cl}_{2}}
$$

Figure 3. Asymmetric hydrogenation of diallyl sulfone. 


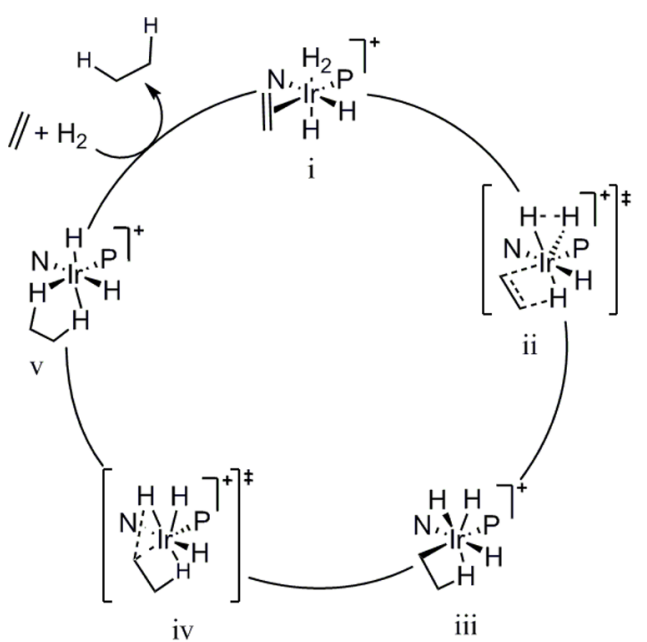

A

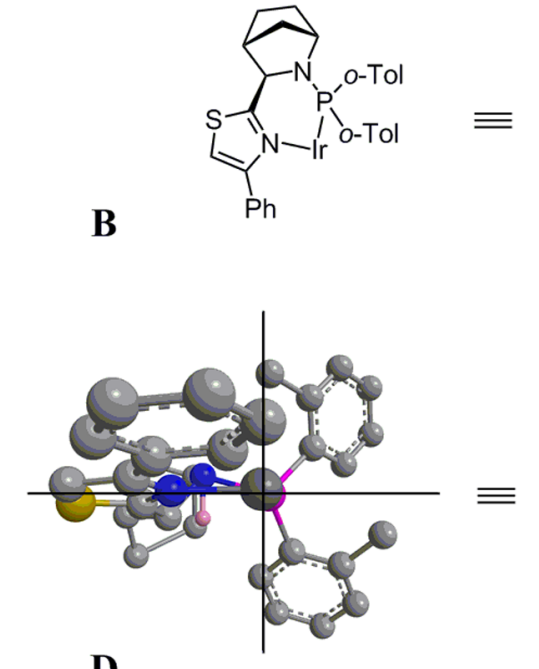

D
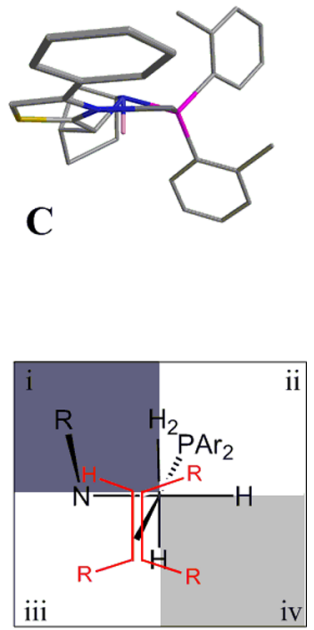

E

Figure 5. Origins of selectivity.

This model has proved reliable to predict the stereochemical outcome for the hydrogenation of a large variety of di- and trisubstituted olefins and has also proved successful in this study.

The results presented in Table 8 show that the stereochemical outcomes of the hydrogenation products are in good

Table 8. Correlation of Observed and Predicted Absolute Configurations

\begin{tabular}{|c|c|c|c|c|c|c|}
\hline Entry & Substrate & $\mathrm{R}^{1}$ & $\mathrm{R}^{2}$ & $\%$ ee & $\begin{array}{l}\text { Observed } \\
\text { abs. conf. }\end{array}$ & $\begin{array}{l}\text { Predicted } \\
\text { abs. conf. }\end{array}$ \\
\hline 1 & & $\mathrm{Bn}$ & $\mathrm{Ph}$ & $96(+)$ & $S$ & $S$ \\
\hline 2 & & $\mathrm{Bn}$ & $n-\mathrm{Bu}$ & $93(+)$ & $S$ & $S$ \\
\hline 3 & & $\mathrm{Bn}$ & $\mathrm{Cy}$ & $86(+)$ & $S$ & $S$ \\
\hline 4 & & $\mathrm{Bn}$ & $i-\operatorname{Pr}$ & $71(+)$ & $S^{a}$ & $S$ \\
\hline 5 & & $\mathrm{Ph}$ & $\mathrm{Ph}$ & $94(-)$ & $S$ & $S$ \\
\hline 6 & & $\mathrm{Bn}$ & $\mathrm{Ph}$ & $96(-)$ & $\mathrm{R}$ & $\mathrm{R}$ \\
\hline 7 & & $\mathrm{Bn}$ & $n-\mathrm{Bu}$ & $83(-)$ & $\mathrm{R}$ & $\mathrm{R}$ \\
\hline 8 & & $\mathrm{Ph}$ & $\mathrm{Ph}$ & $89(+)$ & $\mathrm{R}$ & $\mathrm{R}$ \\
\hline
\end{tabular}

${ }^{a}$ Tentatively assigned by matching the sign of the specific rotation and order of elution for major and minor enantiomers from the chiral column.

agreement with those found in the literature (entries 1-3, 68 ). On the basis of tentative assignment by matching the sign of the specific rotation and order of elution for major and minor enantiomers from the chiral column, the stereochemistry of some other hydrogenated sulfones was determined. These were also found to be in agreement with predicted stereochemistry (entries 4-5).

\section{CONCLUSION}

In this paper, we have reported the highly successful hydrogenation of unsaturated sulfones using an N,P-ligated Ir-catalyst. Excellent ee's and high conversions were obtained for vinylic, allylic and homoallylic sulfones. Low sensitivity to size of the various substituent groups was observed. Overall, we believe that the method described is highly flexible and adaptable to preparative synthetic chemistry.

\section{ASSOCIATED CONTENT}

S Supporting Information

General methods; preparation of substrates and racemates; procedure for asymmetric hydrogenation; characterization of new compounds; table of references for some prepared compounds; NMR spectra and HPLC and GC chromatograms. This material is available free of charge via the Internet at http://pubs.acs.org.

\section{AUTHOR INFORMATION}

\section{Corresponding Author}

phera@organ.su.se

\section{Author Contributions}

${ }^{\S}$ B.K.P. and T.Z. contributed equally to this work.

Notes

The authors declare no competing financial interest.

\section{ACKNOWLEDGMENTS}

Energimyndigheten (The Swedish Energy Agency), Nordic Energy Research (N-INNER II), The Swedish Research Council (VR), The Knut and Alice Wallenberg Foundation, Olle Engkvist Foundation and VR/SIDA for supporting this work. Dr Taigang Zhou thanks the China Scholarship Council for a fellowship. Dr Rujirawanich thanks Erasmus Mundus Action II, EXPERTS II project for a postdoctoral scholarship. Dr Thishana Singh would like to thank the University of KwaZulu-Natal (UKZN), Department of Agriculture, Engineering and Science, as well as the National Research Foundation (NRF), South Africa for a postdoctoral scholarship.

\section{REFERENCES}

(1) Blakemore, P. R. J. Chem. Soc., Perkin Trans. 1 2002, 2563-2585.

(2) Taylor, R. J. K.; Casy, G. Org. React. (N.Y., Engl. Transl.) 2003, 62, 357-475.

(3) Carretero, J. C.; Arrayás, R. G.; Adrio, J. In Organosulfur Chemistry in Asymmetric Synthesis; Wiley-VCH Verlag GmbH \& Co. KGaA: Weinheim, Germany, 2009; pp 291-320.

(4) Doswald, S.; Estermann, H.; Kupfer, E.; Stadler, H.; Walther, W.; Weisbrod, T.; Wirz, B.; Wostl, W. Bioorg. Med. Chem. 1994, 2, 403410.

(5) Grigg, R. Tetrahedron: Asymmetry 1995, 6, 2475-2486. 
(6) Llamas, T.; Arrayas, R. G.; Carretero, J. C. Org. Lett. 2006, 8, 1795-1798.

(7) Shimizu, I.; Ohashi, Y.; Tsuji, J. Tetrahedron Lett. 1984, 25, $5183-5186$.

(8) Kennedy, M.; McKervey, M. A.; Maguire, A. R.; Roos, G. H. P. J. Chem. Soc., Chem. Commun. 1990, 361-362.

(9) Honma, M.; Sawada, T.; Fujisawa, Y.; Utsugi, M.; Watanabe, H.; Umino, A.; Matsumura, T.; Hagihara, T.; Takano, M.; Nakada, M. J. Am. Chem. Soc. 2003, 125, 2860-2861.

(10) Honma, M.; Nakada, M. Tetrahedron Lett. 2003, 44, 90079011.

(11) Sawada, T.; Nakada, M. Adv. Synth. Catal. 2005, 347, 15271532.

(12) Takeda, H.; Watanabe, H.; Nakada, M. Tetrahedron 2006, 62, 8054-8063.

(13) Takano, M.; Umino, A.; Nakada, M. Org. Lett. 2004, 6, 48974900.

(14) Mauleon, P.; Carretero, J. C. Org. Lett. 2004, 6, 3195-3198.

(15) Mauleon, P.; Alonso, I.; Rodriguez, R. M.; Carretero, J. C. J. Org. Chem. 2007, 72, 9924-9935.

(16) Mauleon, P.; Carretero, J. C. Chem. Commun. 2005, 4961-4963.

(17) Mosse, S.; Alexakis, A. Org. Lett. 2005, 7, 4361-4364.

(18) Mossé, S.; Laars, M.; Kriis, K.; Kanger, T.; Alexakis, A. Org. Lett. 2006, 8, 2559-2562.

(19) Li, H. M.; Song, J.; Liu, X. F.; Deng, L. J. Am. Chem. Soc. 2005, 127, 8948-8949.

(20) Liu, T. Y.; Long, J.; Li, B. J.; Jiang, L.; Li, R.; Wu, Y.; Ding, L. S.; Chen, Y. C. Org. Biomol. Chem. 2006, 4, 2097-2099.

(21) Watanabe, Y.; Mase, N.; Furue, R; Toru, T. Tetrahedron Lett. 2001, 42, 2981-2984.

(22) Sugimoto, H.; Nakamura, S.; Watanabe, Y.; Toru, T. Tetrahedron: Asymmetry 2003, 14, 3043-3055.

(23) Jacobsen, E. N.; Pfaltz, A.; Yamamoto, H. Comprehensive Asymmetric Catalysis: I-III; Springer: Berlin, 1999.

(24) Ojima, I. Catalytic Asymmetric Synthesis; 3rd ed.; John Wiley \& Sons Inc.: Hoboken, NJ, 2010.

(25) Roseblade, S. J.; Pfaltz, A. Acc. Chem. Res. 2007, 40, 1402-1411.

(26) Woodmansee, D. H.; Pfaltz, A. Top. Organomet. Chem. 2011, 34, $31-76$.

(27) Cadu, A.; Andersson, P. G. J. Organomet. Chem. 2012, 714, 311.

(28) Etayo, P.; Vidal-Ferran, A. Chem. Soc. Rev. 2013, 42, 728-754.

(29) Cadu, A.; Andersson, P. G. Dalton Trans. 2013, 42, 1434514356.

(30) Trifonova, A.; Diesen, J. S.; Chapman, C. J.; Andersson, P. G. Org. Lett. 2004, 6, 3825-3827.

(31) Kallstrom, K.; Munslow, I. J.; Hedberg, C.; Andersson, P. G. Adv. Synth. Catal. 2006, 348, 2575-2578.

(32) Cheruku, P.; Gohil, S.; Andersson, P. G. Org. Lett. 2007, 9, 1659-1661.

(33) Engman, M.; Diesen, J. S.; Paptchikhine, A.; Andersson, P. G. J. Am. Chem. Soc. 2007, 129, 4536-4537.

(34) Cheruku, P.; Church, T. L.; Trifonova, A.; Wartmann, T.; Andersson, P. G. Tetrahedron Lett. 2008, 49, 7290-7293.

(35) Cheruku, P.; Paptchikhine, A.; Church, T. L.; Andersson, P. G. J. Am. Chem. Soc. 2009, 131, 8285-8289.

(36) Engman, M.; Cheruku, P.; Tolstoy, P.; Bergquist, J.; Volker, S. F.; Andersson, P. G. Adv. Synth. Catal. 2009, 351, 375-378.

(37) Paptchikhine, A.; Cheruku, P.; Engman, M.; Andersson, P. G. Chem. Commun. 2009, 5996-5998.

(38) Verendel, J. J.; Zhou, T. G.; Li, J. Q.; Paptchikhine, A.; Lebedev, O.; Andersson, P. G. J. Am. Chem. Soc. 2010, 132, 8880.

(39) Lightfoot, A.; Schnider, P.; Pfaltz, A. Angew. Chem., Int. Ed. 1998, 37, 2897-2899.

(40) Cadu, A.; Paptchikhine, A.; Andersson, P. G. Synthesis 2011, 2011, 3796-3800.

(41) Cadu, A.; Upadhyay, P. K.; Andersson, P. G. Asian J. Chem. 2013, 2, 1061-1065.
(42) Bernasconi, M.; Ramella, V.; Tosatti, P.; Pfaltz, A. Chem.-Eur. J. 2014, 20, 2440-2444.

(43) Dieguez, M.; Mazuela, J.; Pamies, O.; Verendel, J. J.; Andersson, P. G. J. Am. Chem. Soc. 2008, 130, 7208-7209.

(44) Kaukoranta, P.; Engman, M.; Hedberg, C.; Bergquist, J.; Andersson, P. G. Adv. Synth. Catal. 2008, 350, 1168-1176.

(45) Brandt, P.; Hedberg, C.; Andersson, P. G. Chem.—Eur. J. 2003, 9, 339-347.

(46) Church, T. L.; Rasmussen, T.; Andersson, P. G. Organometallics 2010, 29, 6769-6781.

(47) Fan, Y.; Cui, X.; Burgess, K.; Hall, M. B. J. Am. Chem. Soc. 2004, $126,16688-16689$.

(48) Gruber, S.; Pfaltz, A. Angew. Chem., Int. Ed. 2014, 53, 18961900.

(49) Mazuela, J.; Norrby, P.-O.; Andersson, P. G.; Pàmies, O.; Diéguez, M. J. Am. Chem. Soc. 2011, 133, 13634-13645.

(50) Bertus, P.; Phansavath, P.; Ratovelomanana-Vidal, V.; Genet, J. P.; Touati, A. R.; Homri, T.; Ben Hassine, B. Tetrahedron Lett. 1999, 40, 3175-3178.

(51) Genêt, J. P.; Pinel, C.; Ratovelomanana-Vidal, V.; Mallart, S.; Pfister, X.; Bischoff, L.; De Andrade, M. C. C.; Darses, S.; Galopin, C.; Laffitte, J. A. Tetrahedron: Asymmetry 1994, 5, 675-690.

(52) Genêt, J. P.; Pinel, C.; Ratovelomanana-Vidal, V.; Mallart, S.; Pfister, X.; De Andrade, M. C. C.; Laffitte, J. A. Tetrahedron: Asymmetry 1994, 5, 665-674.

(53) Zhang, H. L.; Hou, X. L.; Dai, L. X.; Luo, Z. B. Tetrahedron: Asymmetry 2007, 18, 224-228.

(54) Misun, M.; Pfaltz, A. Helv. Chim. Acta 1996, 79, 961-972.

(55) Llamas, T.; Arrayás, R. G.; Carretero, J. C. Angew. Chem., Int. Ed. 2007, 46, 3329-3332.

(56) Hou, G.-H.; Xie, J.-H.; Yan, P.-C.; Zhou, Q.-L. J. Am. Chem. Soc. 2009, 131, 1366-1367.

(57) Hou, G.; Li, W.; Ma, M.; Zhang, X.; Zhang, X. J. Am. Chem. Soc. 2010, 132, 12844-12846.

(58) Zhou, T.; Peters, B.; Maldonado, M. F.; Govender, T.; Andersson, P. G. J. Am. Chem. Soc. 2012, 134, 13592-13595.

(59) Crabtree, R. Acc. Chem. Res. 1979, 12, 331-337.

(60) Li, J. Q.; Paptchikhine, A.; Govender, T.; Andersson, P. G. Tetrahedron: Asymmetry 2010, 21, 1328-1333. 